\title{
Long-term stability of 14YT-4Sc alloy at high temperature
}

\author{
Lulu Li ${ }^{* a}$, Weizong Xua ${ }^{\mathrm{a}}$, Mostafa Saber ${ }^{\mathrm{b}}$, Yuntian Zhu', Carl C. Koch ${ }^{\mathrm{a}}$, Ronald O. Scattergood ${ }^{\mathrm{a}}$
}

${ }^{a}$ Department of Materials Science and Engineering, North Carolina State University, 911 Partners Way, Room 3002, Raleigh, NC 27695-7907, USA

${ }^{b}$ Department of Mechanical and Materials Engineering, Portland State University, Post Office Box 751, Portland, OR 97207,USA

* Corresponding author. Tel.:+1-919-749-5018; fax:+1-919-515-7724. E-mail address: lli18@ncsu.edu (Lulu Li)

\begin{abstract}
14YT alloy (Fe-14Cr-0.25wt.\% $\left.\mathrm{Y}_{2} \mathrm{O}_{3}-0.4 \mathrm{wt} . \% \mathrm{Ti}\right)$ with 4at.\% Sc addition was previously reported to exhibit ananoscale microstructure and high strength when annealed at temperatures up to $1000{ }^{\circ} \mathrm{C}\left(0.65 \mathrm{~T}_{\mathrm{m}}\right)$ for 1 hour.Here we report that the microstructure and mechanical behavior of 14YT-4Sc alloy after long-term annealing for up to 60 hours at $1000{ }^{\circ} \mathrm{C}$. FIB analysisshowsabnormal graingrowth with annealing time, while a large fraction of the matrix still consists ofnanoscale grains. TEM images reveala slightgrowth of nano grains, with estimated grain growth exponent, $n$, to be 0.29 . Sc-Ti-Y-O enriched nano oxide particles $(<10$ $\mathrm{nm})$ were observed in EDS mapping of the 14YT-4Sc-60h sample. The nano-structure retentionat the high temperature of $1000{ }^{\circ} \mathrm{C}$ for 60 hours is attributed to these complex nano oxides.
\end{abstract}


Keywords: Nanocrystalline ODS ferriticalloys; Grain growth; Sc stabilization; long-term stability

\section{Introduction}

ODS ferritic steels, with excellent creep strength[1,2] and high resistance to irradiation, have been the focus of extensive research for possible structural applications in generation IV fission and fusion reactors $[3,4]$. A major requirement for this class of steels is to have high microstructural stability in order to withstand a very hostile environment such as high neutron fluxes and elevated temperatures[5].

Grain growth falls into two categories: normal grain growth, where grainsgrow almost uniformly[6]; and abnormal grain growth, where "abnormally large grains" may nucleate and grow at the expense of a relatively fine matrix [7]. This abnormal grain growth may be caused by a local low pinning force $[8,9]$, resulting in a large growth rate. It appears that an abnormal grain can develop from a matrix where normal grain growth took place, indicating that no initial size advantage is needed [10]. It is suggested that normal grain growth should ideally follow a parabolic relationship $[6,11]$ :

$D^{2}-D_{0}^{2}=K t(1)$

where $\mathrm{D}$ is themean grain size at time $\mathrm{t}, \mathrm{D}_{0}$ is the initial mean grain size and $\mathrm{K}$ is a temperature dependent rate constant. However, in practice, the experimental data for isothermal grain growth has been fit to apower-law incorporating the time exponent $\mathrm{n}(\leq 0.5)[12]$ :

$D^{1 / n}-D_{0}^{1 / n}=K t(2)$

The parameter $\mathrm{n}$ depends on the grain growth mechanisms[6, 13, 14], which may be influenced by residual strain, grain boundary energy and pinning force as a result of second phase particles 
or solute drag[15]. Research and theories suggest that the growth rate of nanomaterials can be retarded by the solute drag effect and vacancy generation model [16]. The kinetics of grain growth in pure ball-milled Fe has been reported to show good agreement with the excess-volume model, with linear growth at small grain sizes and transferring to nonlinear kinetics when the grain size $>150 \mathrm{~nm}[17]$.

Previous researches have investigated the addition of $\operatorname{Zr}[18,19]$ and $\mathrm{Hf}[20,21]$ elements to the ball milled $\mathrm{Fe}-14 \mathrm{Cr}$ base alloy in context with the thermodynamic stabilization ternary model[22, 23]. It is found that $\mathrm{Zr} / \mathrm{Hf}$ additions help to stabilize a nano microstructure at up to $900{ }^{\circ} \mathrm{C}$ and $1000{ }^{\circ} \mathrm{C}$, respectively. Sc is alsopredicted to be a strong stabilizer to the $\mathrm{Fe}-\mathrm{Cr}$ alloybased on the model[22, 23] and $14 \mathrm{YT}\left(\mathrm{Fe}-14 \mathrm{Cr}-0.25 \mathrm{wt} . \% \mathrm{Y}_{2} \mathrm{O}_{3}-0.4 \mathrm{wt} . \% \mathrm{Ti}\right)$ ODS alloy with Sc addition was reported to have good microstructural and mechanical stability after high temperatureannealing[24]. The high temperature stabilization is mainly attributed to the presence of a dispersion of [ScTiO] nanoclusters. These nanoclusters exert pinning forces on grain boundaries, thereby inhibiting grain coarsening. The grain growth may occur, when second phase particles coarsen[25] caused by Ostwald ripening[26] or when chemical modifications of the matrix result in less solute drag [5,27]. At high temperatures, the solute drag effect is negligible. Therefore, the size distribution of second phase nanoclusters is one of the key stabilizers of the 14YT-4Sc alloy in this work. However, there are very few reports on the grain growth behavior of ODS ferritic alloys in the literature, especially no detailed study regarding the effects of long-term thermal exposure on the 14YT-4Sc alloy.

In this work, an isothermal annealingat $1000^{\circ} \mathrm{C}\left(0.65 \mathrm{~T}_{\mathrm{m}}\right)$ was carried out on $14 \mathrm{YT}-4 \mathrm{Sc}$ samples from 1 hour to 60 hours. The subsequent evolution of microstructure and mechanical property (hardness) was investigated. The study of grain growth behavior of nanocrystalline 14YT-4Sc 
alloy can facilitate hot compaction of mechanically alloyed powders into fully dense nanostructured compacts [15]. High pressures/temperatures are needed for consolidating and sintering such high hardness alloys [28]. Whilethe temperature studied in this work $\left(1000{ }^{\circ} \mathrm{C}\right)$ is higher than expected under service conditions in reactors [29], it is relevant to study the longterm thermal stability of 14YT-4Sc alloy.

\section{Experimental}

The alloy studied in this work, Fe-14Cr-4Sc-0.25wt. $\% \mathrm{Y}_{2} \mathrm{O}_{3}-0.4 \mathrm{wt} . \% \mathrm{Ti}$, will be referred to as 14YT-4Sc hereafter. Powders used for the long term annealing study were mechanically alloyed using a SPEX SamplePrep 8000M Mixer/Mill [24]. After 20hours milling, the as-milled powders were subjected to isothermalannealing at $1000{ }^{\circ} \mathrm{C}$ for $1 \mathrm{~h}, 10 \mathrm{~h}, 15 \mathrm{~h}, 24 \mathrm{~h}$, and $60 \mathrm{~h}$ under $\mathrm{Ar}-2 \% \mathrm{H}_{2}$ environment, and these will be designated as $14 \mathrm{YT}-4 \mathrm{Sc}-\mathrm{Xh}(\mathrm{X}=1,10,15,24,60)$. The annealing wasdone in a Lindberg tube furnace with a thermocouple to monitor the temperature. Powders were covered with a piece of $Z r$ foil, so as to avoid reaction with excess oxygen during the annealing procedure, and placed into a quartz tube. Subsequent cooling was conducted at room temperature by moving the tubeaway from the furnace. X-ray diffraction was done for both as-milled and annealed samples using a Rigaku Smartlab X-ray diffractometer with $\mathrm{Cu}_{\alpha}$ radiation. The Williamson-Hall method [30]was applied to estimate grain size and microstrain from the XRD data. Micro-hardness was measured with a 50g load. The variation of grain size with annealing time was determined by both focused ion beam channeling contrast imaging (FIB-CCI) and TEM. The FEI Quanta 200 3D FEG dual-beam FIB system measures a relatively large area to show grain size distribution and abnormal grain growth. Image contrast was resulted from the changes in the grain orientations, leading to variations in ion channeling efficiency [31]. TEM images were obtained using a JEM-2010F microscope to more 
preciselycharacterize the average nano grain sizes and their distribution. More detailed EDS elemental mapping and HAADF-STEM images were obtained using an aberration-corrected FEI Titan G2 microscope at $200 \mathrm{kV}[32]$.

\section{Results and discussion}

The grain size andmicrostrain obtained from XRD and the corresponding Vickers microhardness as a function of annealing time are shown in Fig. 1(a) and (b), respectively.For the as-milled condition, the average grain size is about $25 \pm 5 \mathrm{~nm}$ with the highest microstrain of $0.67 \%$. The grain sizein Fig. 1(a) increases with longer annealing and nanograins were maintained for up to 20h. In the first hour of annealing, the grain growth occurs very fast, which can be attributed to subgrain incorporation [33]. Coincident with the initial rapid grain growth, the microstrain decreases sharply at the beginning of annealing due to the annihilation of dislocations[34],and then drops slowly with annealing time. Krill et al. [17] suggested that the decrease of dislocation density annealinggives rise tohigh grain growth rate. In Fig. 1(b), the change in micro-hardness is consistent with the trend of microstrain in Fig. 1(a), which decreases significantly at first and then exhibits remarkable stability after long term annealing. Only a $1.64 \pm 0.58 \mathrm{GPa}$ drop in hardness is observed from the $14 \mathrm{YT}-4 \mathrm{Sc}-1 \mathrm{~h}$ sample to the $14 \mathrm{YT}-4 \mathrm{Sc}-60 \mathrm{~h}$ sample. This indicates that the 14YT-4Sc alloy possesses high thermal stability.

To further study the microstructural evolution during annealing, large-area FIB ion contrast imaging wasused. Fig.2 (a) to (e) shows the grain size distribution of 14YT-4Sc with increasing annealing time from $1 \mathrm{~h}$ to $60 \mathrm{~h}$, respectively. The $14 \mathrm{YT}-4 \mathrm{Sc}-1 \mathrm{~h}$ sample in Fig. 2(a), displays a uniform grain size throughout the entire region, while after 10h annealing Fig. 2(b) shows large grains in some regions marked by red arrows, indicating abnormal grain growth. The size 
distribution of grains above the nanoscale $(>100 \mathrm{~nm})$ isplotted in Fig. $2(\mathrm{~g})$. As the grains grew larger upon annealing, the size distribution range above the nanoscale becomes broader. An average grain size in this range for $10 \mathrm{~h}, 15 \mathrm{~h}, 24 \mathrm{~h}$, and $60 \mathrm{~h}$ annealing times were estimated from Fig. $2(\mathrm{~g})$ to be $0.4,0.52,0.63$ and $1.18 \mu \mathrm{m}$, respectively. Apart from those grains, a large fraction of nanoscale grains can still be observed even after $60 \mathrm{~h}$ annealing. These nanoscale grain sizesprovide for a primary contribution to the mechanical properties after high temperature annealing. The area fraction of micron grains and nano grains at different annealing times weremeasured using FIB images, and are plotted in Fig. 2(f). The area fraction of micron grains (blue column) increases with annealing times. Nevertheless, the nano grains (red column) dominate, illustratingthe remarkable stability of the 14YT-4Sc alloy.

Figs.3(a) to(d) are TEM bright field images of 14YT-4Sc annealed at $1 \mathrm{~h}, 15 \mathrm{~h}, 24 \mathrm{~h}$ and $60 \mathrm{~h}$, respectively, taken from the nanocrystalline region. Grain size in this region increases slightly with increasing annealing time. Numerous small dispersoids are observed. Nano grain size and dispersoid size were estimated by statistical counting of more than 200 examples for each sample using TEM dark field images. The statistical histograms of nano grain size and dispersoid size distributions are shown in Fig. 4(a) and (b), respectively. The mean grain/ particle size shifts to larger values and their distribution becomes broader with annealing. For the $14 \mathrm{YT}-4 \mathrm{Sc}-15 \mathrm{~h}$ sample, the average nano grains grow from $32 \mathrm{~nm}$ to $47 \mathrm{~nm}$ compared to the $14 \mathrm{YT}-4 \mathrm{Sc}-1 \mathrm{~h}$ sample, whilethedispersoid size shows limited coarsening from $4 \mathrm{~nm}$ to $6 \mathrm{~nm}$. Although the dispersoids exhibit growth, these are still extremely small and can exert strong pinning pressure on grain boundaries to mitigate grain growth. The stability is also reflected in the small hardness drop of $0.57 \pm 0.26 \mathrm{GPa}$ from the $14 \mathrm{YT}-4 \mathrm{Sc}-1 \mathrm{~h}$ to the $14 \mathrm{YT}-4 \mathrm{Sc}-15 \mathrm{~h}$ samples. The average nano grain size of $14 \mathrm{YT}-4 \mathrm{Sc}-24 \mathrm{~h}$ and $60 \mathrm{~h}$ are estimated to be $70 \mathrm{~nm}$ and $76 \mathrm{~nm}$ with dispersoid size of 
6.8 , and $9.7 \mathrm{~nm}$, respectively. The small nanoclusters $(<10 \mathrm{~nm})$ maintain a relatively high resistance to particle growth at high temperatures. The stability of the dispersoids after long-term thermal annealing is beneficial for the stability of bothmicrostructures and mechanical properties of the 14YT-4Sc alloy.

The average micrometer grain size and nanometer grain size for different annealing times of 14YT-4Sc samples are plotted separately in Fig.5(a). Nanoscale grainsgrow slightly, while micronscale grain sizebecomes significantly larger, indicating that the growth rate of nano grains is much slower. Beck et al.[12]proposed the grain growth equation (2) including the empirical time exponent $\mathrm{n}$ to allow for the description of isothermal grain growth. Equation (2) can be rewritten as:

$\log (d D / d t)=\log (K)+\log (n)+(1-1 / n) \log (D)(3)$

The constant $\mathrm{n}$ for each alloy system can be obtained from the slope of the curve of $\log (\mathrm{dD} / \mathrm{dt})$ vs. $\log (\mathrm{D})$. Equation (3) predicts that the rate of grain growth is related to the instantaneous grain size D i.e., grain size dependent growth. The datafor nanograins in Fig. 5(a) was used to plotthelog $(\mathrm{dD} / \mathrm{dt})$ term as a function of $\log (\mathrm{D})$, as shown in Fig.5(b). The $\mathrm{n}$ value is 0.29, calculated from the slope of the straight line.This deviates fromthe theoretical value of 0.5 for ideal grain growth[15]. Malow and Koch [15] reported ann valuefor nanocrystalline Feprepared by mechanical attrition thatincreased to 0.33 at a temperature of $0.45 \mathrm{~T}_{\mathrm{m}}$, and then increased to 0.5 when $\mathrm{T}>0.45 \mathrm{~T}_{\mathrm{m}}$. Here, $14 \mathrm{YT}$ with 4 at.\% Sc addition manifests a much lower $\mathrm{n}$ value in a very high temperature of $0.65 \mathrm{~T}_{\mathrm{m}}$, demonstrating greater resistance to grain growth with time. The mechanismsfor the inhibited grain boundary migration rate can be residual strains [35], anisotropic grain boundary energy [36], solute drag effect [37] and pinning forces exerted by 
second phase particles. In this work, the second phase particles are the likely major source for maintaining $n$ constant.

After high temperature annealing for long times, the grain size and the second phase particles would be the primary contributions to the strengthening. The hardness data is plotted in Fig.6 as a function of annealing time. The grain size effect can beevaluated using theHall-Petchequation (4) from the base alloy Fe-14Cr [20]:

$H=H_{0}+k D^{-1 / 2}(4)$

$\mathrm{D}$ is the average grain size, $\mathrm{H}_{0}=2.31 \mathrm{GPa}$ and $\mathrm{k}=22.35 \mathrm{GPa} \mathrm{nm}^{1 / 2}$. The grain size strengthening effect is calculated by combiningthe nano grain size and micron grain size contributions to hardness, based on the ratio of their area fractions. Orowan strengthening can also contribute to the total hardness. This can be evaluated using the Zener pinning model to estimate the volume fraction of nanoparticles. According to the Zener pinning model [38]:

$\mathrm{D} / d=\mathrm{Z} / f^{m}(5)$

By inputting the nanograin size D and nanoparticle size $d$ in equation (5), we estimate the volume fraction $\mathrm{f}$ of particles needed to maintain $\mathrm{D}$. For Fe-based alloys, $\mathrm{Z}$ is 0.17 and $\mathrm{m}=1$ if $\mathrm{f}$ $<0.05$ [38]. The Orowan strengthening contribution is:

$H_{\text {oro }}=3 \sqrt{3}\left(\frac{\ln \left(\mathrm{d} / r_{0}\right)}{\ln \left(\mathrm{L} / r_{0}\right)}\right)^{3 / 2} \frac{\mathrm{Gb}}{\mathrm{L}} \frac{\ln \left(L / r_{0}\right)}{2 \pi}(6)$

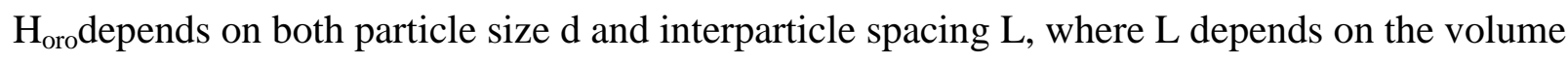
fraction $\mathrm{f}$ : 
$L=d\left[(\pi / 4 f)^{\frac{1}{2}}-1\right](7)$

The Orowan strengthening effect is then obtained for each annealing time, and is plotted in Fig.6. It can be seen that Orowan strengthening makes a small and nominally constant contribution to the hardness for all annealing times.

Nano dispersoids are further characterized in theHAADF-STEM imagesshown in Fig.7. Increasing the annealing time from 1h shown in Fig. 7(a) to 60h shown in Fig. 7 (b) led to subsequent matrix and dispersoid coarsening. The majority of nanoclusters are observed along thegrain boundaries of nanograins, both in the 14YT-4Sc-1h and 14YT-4Sc-60h samples. In the 14YT-4Sc-1h sample, several small second phase particles can be observed within the matrix. At the longer the annealing time, a cleaner region within the matrix is observed, implying that nanoparticle phases prefer to reside along grain boundaries. The high resolution image shown in Fig. 7(b) confirms that almost all nanoparticles help reduce nanograin growth. Furthermore, a locally inhomogeneous distribution of dipsersoids appeared in the 14YT-4Sc-60h sample marked by red arrows in Fig. 7(b).Grain boundary migration caused by the absence of pinning sites, which results from the inhomogeneous distribution of nanoparticles (nanoclusters)indicated in Fig. 7(b). This nonuniform distribution could arise in two ways. First is the "statistical effect" [10] wherein variationoccurs fromregion to region. Even if the microstructure is uniform initially, particular grains can find a growth advantage with locally a lower than average pinning force. Second is the "true" microstructural heterogeneity. Since no strong crystallographic texture is achieved after high-energy ball milling and no stress is applied during heat treatment, the inhomogeneous distribution of nanoclusters evolvesthe first way. Anomalously large grainscan 
appear once an initial small grain grows beyond a critical size and it can continue to grow at the expense of neighboring small grains.

EDS mapping of each element in the 14YT-4Sc-60h sample is shown in Fig. 8 to reveal the composition of the nanoclusters. The composition of these nanoclusters are [ScTiYO], depleted of Fe and Cr.For the long-time annealed alloy (60h), Sc atoms are observed mainly in the nanoclusters while Y atoms only show slight segregation tendency to nanoclusters. This preference is also seen in the short term annealed sample [24], which could be explained by the large difference of the element content $(\mathrm{Sc} / \mathrm{Y})$ added and the strong affinity between $\mathrm{Sc}$ and $\mathrm{O}$. In addition, after $60 \mathrm{~h}$ annealing, no intermetallics were observed, suggesting the possibility of good mechanical proprieties.

Hayashi et al. [1] have observed nanoclusters segregating at the grain boundaries and forming a chain-like structure which inhibits grain growth at $\mathrm{T}>0.6 \mathrm{~T}_{\mathrm{m}}$. The chain-like features are alsoobserved here in the $1 \mathrm{~h}$ annealed sample, prior to anomalous grain growth, and this becomesclearer in the nanoscale region for the $60 \mathrm{~h}$ annealed sample. Itsuggests that the enhanced nucleation at and diffusion along the grain boundaries aid in nanoclusters forming preferentially on grain boundaries [39]. Therefore, a three-dimensional chain-like network can be formed during annealing. In this way, nano-structures during long term annealing are strongly pinned and stabilized by the nanoclusters' network. Even though abnormal grain growth has occurred, those nanoclusters provide a strong interaction with boundaries. Thus, there is no dramatic difference in nano grain size for short-term annealed and long-term annealed samples(both of themon the order of $100 \mathrm{~nm}$ ). The stability of nano grain size is due to the high thermal stability of nanoclusters to resist growth upon annealing. In 14YT-4Sc-1h sample [24], the Y element is not observed in [ScTiO] nanoclusters, thus most yttrium atoms must be either in solid solution or 
in the form of very small clusters that were not resolved by EDS elemental mapping. In the longterm thermal annealing, $\mathrm{Y}$ diffused to the dispersoids, forming more complex nanoclusters, as indicated in Fig. 8. The segregated $\mathrm{Y}$ atoms may also help stabilize initial nanolcusters by forming complex ternary oxides. Further investigationwill be needed to evaluate long-term irradiation performance of 14YT ODS ferrtic alloys with Sc addition for fusion reactors application.

\section{Conclusions}

The microstructural and mechanical long-term stability of $14 \mathrm{YT}-4 \mathrm{Sc}$ has been studied. Abnormal grain growth was observed with increasing annealing time. However, a stabilized nanoscale grain region is found to dominate the matrix with limited grain growth. $\mathrm{n}$ is constant for this stabilized region and is estimated to be 0.29 , at $0.65 \mathrm{~T}_{\mathrm{m}}$, lower than the value expected from the literature. Additionally, the stabilized microstructure leads to subsequent high hardness, such that only a $24.51 \%$ drop in hardness from $1 \mathrm{~h}$ annealed sample to $60 \mathrm{~h}$ one is occurred. The high hardness of 14YT-4Sc-1h alloy can be explained by the formation of fine complex oxides of [ScTiO] due to the Sc addition. After 60 hours annealing, EDS mapping indicates that $\mathrm{Y}$ atoms gradually segregate to nanoclusters, forming more complex oxides [ScTiYO] with extremely small size $(<10 \mathrm{~nm})$.

\section{Acknowledgements}

We are grateful for the financial support from the Department of Energy, Grant DE-NE0000538. The authors also acknowledge the use of the Analytical Instrumentation Facility (AIF) at North Carolina State University, which is supported by the State of North Carolina and the National Science Foundation. 


\section{References}

[1] T. Hayashi, P.M. Sarosi, J.H. Schneibel, M.J. Mills, Acta Materialia, 56 (2008) 1407-1416.

[2] J.H. Schneibel, C.T. Liu, M.K. Miller, M.J. Mills, P. Sarosi, M. Heilmaier, D. Sturm, Scripta Materialia, 61 (2009) 793-796.

[3] R.L. Klueh, D.S. Gelles, S. Jitsukawa, A. Kimura, G.R. Odette, B. van der Schaaf, M. Victoria, Journal of Nuclear Materials, 307-311, Part 1 (2002) 455-465.

[4] R.L. Klueh, A.T. Nelson, Journal of Nuclear Materials, 371 (2007) 37-52.

[5] K.D. Zilnyk, H.R.Z. Sandim, R.E. Bolmaro, R. Lindau, A. Möslang, A. Kostka, D. Raabe, Journal of Nuclear Materials, 448 (2014) 33-42.

[6] H.V. Atkinson, Acta Metallurgica, 36 (1988) 469-491.

[7] A.D. Rollett, D.J. Srolovitz, M.P. Anderson, Acta Metallurgica, 37 (1989) 1227-1240.

[8] M. Hillert, Acta Metallurgica, 13 (1965) 227-238.

[9] P.A. Beck, M. Holzworth, Trans. Am. Inst. Min. Metall. Eng, 180 (1949) 163-192.

[10] P.R. Rios, Acta Materialia, 45 (1997) 1785-1789.

[11] J.E. Burke, D. Turnbull, Progress in Metal Physics, 3 (1952) 220-292.

[12] P.A. Beck, J.C. Kremer, L. Demer, M. Holzworth, Trans. Am. Inst. Min. Metall. Eng, 175 (1948) 372-

400.

[13] H. Natter, M. Schmelzer, M.S. Löffler, C.E. Krill, A. Fitch, R. Hempelmann, The Journal of Physical Chemistry B, 104 (2000) 2467-2476.

[14] R. Monzen, T. Echigo, Materials science forum, Trans Tech Publ, 1998, pp. 609-612.

[15] T.R. Malow, C.C. Koch, Acta Materialia, 45 (1997) 2177-2186.

[16] W. Li, Z. An, X. Wang, Y. Rong, Materials Letters, 62 (2008) 3262-3265.

[17] C.E. Krill, L. Helfen, D. Michels, H. Natter, A. Fitch, O. Masson, R. Birringer, Physical Review Letters, 86 (2001) 842-845.

[18] M. Saber, H. Kotan, C.C. Koch, R.O. Scattergood, Materials Science and Engineering: A, 556 (2012) 664-670.

[19] W.Z. Xu, L.L. Li, M. Saber, C.C. Koch, Y.T. Zhu, R.O. Scattergood, Journal of Nuclear Materials, 452 (2014) 434-439.

[20] L. Li, M. Saber, W. Xu, Y. Zhu, C.C. Koch, R.O. Scattergood, Materials Science and Engineering: A, 613 (2014) 289-295.

[21] W. Xu, L. Li, M. Saber, C. Koch, Y. Zhu, R. Scattergood, Metall and Mat Trans A, (2015) 1-11.

[22] M. Saber, H. Kotan, C.C. Koch, R.O. Scattergood, Journal of Applied Physics, 113 (2013) 063515.

[23] M. Saber, H. Kotan, C.C. Koch, R.O. Scattergood, Journal of Applied Physics, 114 (2013) 103510.

[24] L. Li, W. Xu, M. Saber, Y. Zhu, C.C. Koch, R.O. Scattergood, Materials Science and Engineering: A, 636 (2015) 565-571.

[25] T. Gladman, On the Theory of the Effect of Precipitate Particles on Grain Growth in Metals, 1966.

[26] H. Sakasegawa, F. Legendre, L. Boulanger, M. Brocq, L. Chaffron, T. Cozzika, J. Malaplate, J. Henry, Y. de Carlan, Journal of Nuclear Materials, 417 (2011) 229-232.

[27] E. Nes, N. Ryum, O. Hunderi, Acta Metallurgica, 33 (1985) 11-22.

[28] R. Gupta, R.K. Singh Raman, C.C. Koch, Materials Science and Engineering: A, 494 (2008) 253-256.

[29] R. Lindau, A. Möslang, M. Rieth, M. Klimiankou, E. Materna-Morris, A. Alamo, A.A.F. Tavassoli, C.

Cayron, A.M. Lancha, P. Fernandez, N. Baluc, R. Schäublin, E. Diegele, G. Filacchioni, J.W. Rensman, B.v.d. Schaaf, E. Lucon, W. Dietz, Fusion Engineering and Design, 75-79 (2005) 989-996.

[30] G.K. Williamson, W.H. Hall, Acta Metallurgica, 1 (1953) 22-31.

[31] M.W. Phaneuf, Micron, 30 (1999) 277-288. 
[32] M. Saber, W. Xu, L. Li, Y. Zhu, C.C. Koch, R.O. Scattergood, Journal of Nuclear Materials, 452 (2014) 223-229.

[33] C. Wen, Z. Chen, B. Huang, Y. Rong, Metall and Mat Trans A, 37 (2006) 1413-1421.

[34] G.K. Rane, U. Welzel, E.J. Mittemeijer, Acta Materialia, 60 (2012) 7011-7023.

[35] R. Fullman, American Society for Metals, Metals Park, OH, (1952).

[36] M.W. Shin, T.M. Hare, A.I. Kingon, C.C. Koch, Journal of Materials Research, 7 (1992) 3194-3201.

[37] J.W. Cahn, Acta Metallurgica, 10 (1962) 789-798.

[38] M. PA, T. Chandra, ISIJ international, 38 (1998) 913-924.

[39] M.K. Miller, K.F. Russell, D.T. Hoelzer, Journal of Nuclear Materials, 351 (2006) 261-268.

\section{Figure captions}

Fig. 1(a) XRD-calculated grain sizes, micro strain, and (b) Vickers hardness as a function of annealing time at temperature of $1000{ }^{\circ} \mathrm{C}$ for $14 \mathrm{YT}-4 \mathrm{Sc}$ alloy.

Fig.2(a)-(e) FIB-CCI images showing microstructures of 14YT-4Sc alloy annealed at 1h, 10h, 15h and 24, respectively; Red arrows marked in (e) indicate large grains observed in 14YT-4Sc after $10 \mathrm{~h}$ annealing; (f) shows variation of the area fraction of micron grains and nano grains with annealing times; (g) histogram of number fraction of micron grains.

Fig. 3(a)-(d) Bright-field TEM images focusing on nanocrystalline region of 14YT-4Sc alloy annealed at $1 \mathrm{~h}, 15,24 \mathrm{~h}$ and $60 \mathrm{~h}$, respectively.

Fig. 4(a) and (b) are histograms of number fraction of nano grains and dispersoids, respectively. The average size for each sample is estimated.

Fig. 5(a) Micron grain size and nano grain size for 14YT-4Sc alloy annealed at different times calculated from Fig. 4(a) and (b) are plotted as a function of annealing time; (b) nano grain size data is used to plot $\log (\mathrm{dD} / \mathrm{dt})$ vs. $\log (\mathrm{dD})$ to estimate the grain growth rate for nanocrystalline region. The $\mathrm{n}$ constant calculated from the straight line is 0.29 . 
Fig. 6 Total hardness data and the calculated grain refinement strengthening data from HallPetch equation are plotted with annealing times. The deviation between those two curves is considered to be Orowan strengthening effect.

Fig. 7 HAADF-STEM images of 14 YT-4Sc alloy annealed at $1000{ }^{\circ} \mathrm{C}$ for (a) $1 \mathrm{~h}$ and (b) $60 \mathrm{~h}$. Red arrows indicate the inhomogeneous distribution of nanoclusters after long term thermal treatment.

Fig. 8 HAADF-STEM image and EDS elemental mapping of 14YT-4Sc-60h sample, showing the distribution of $\mathrm{Fe}, \mathrm{Cr}, \mathrm{Sc}, \mathrm{Ti}, \mathrm{Y}$, and $\mathrm{O}$ atoms. 


\section{Figures}

Fig. 1(a)

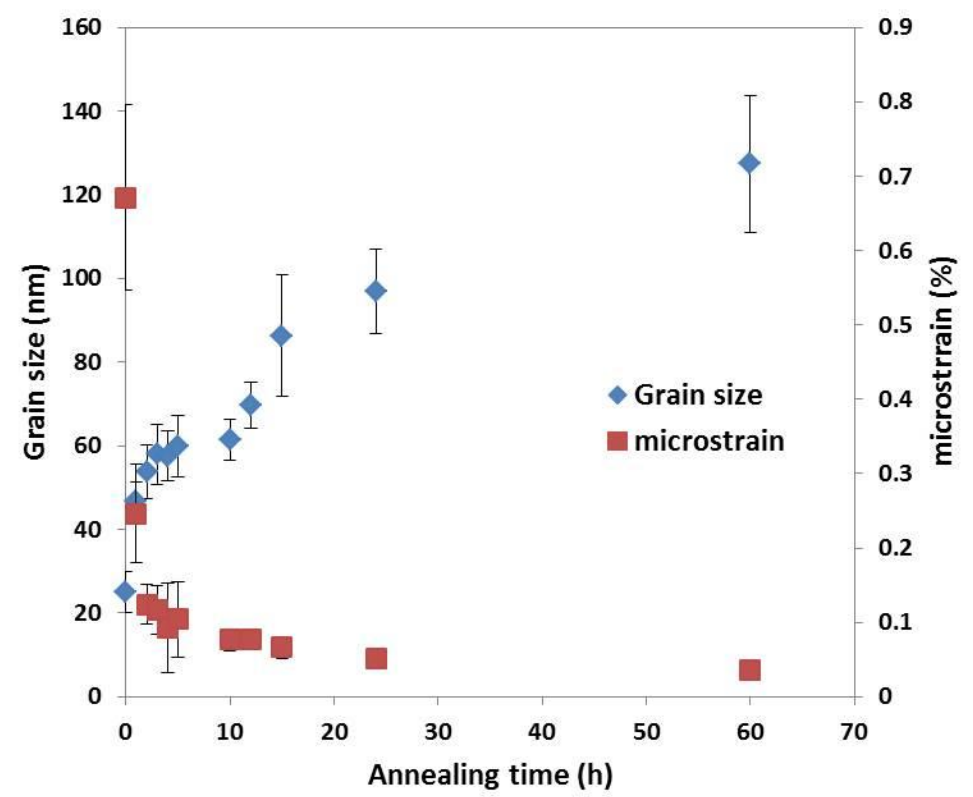

Fig.1(b)

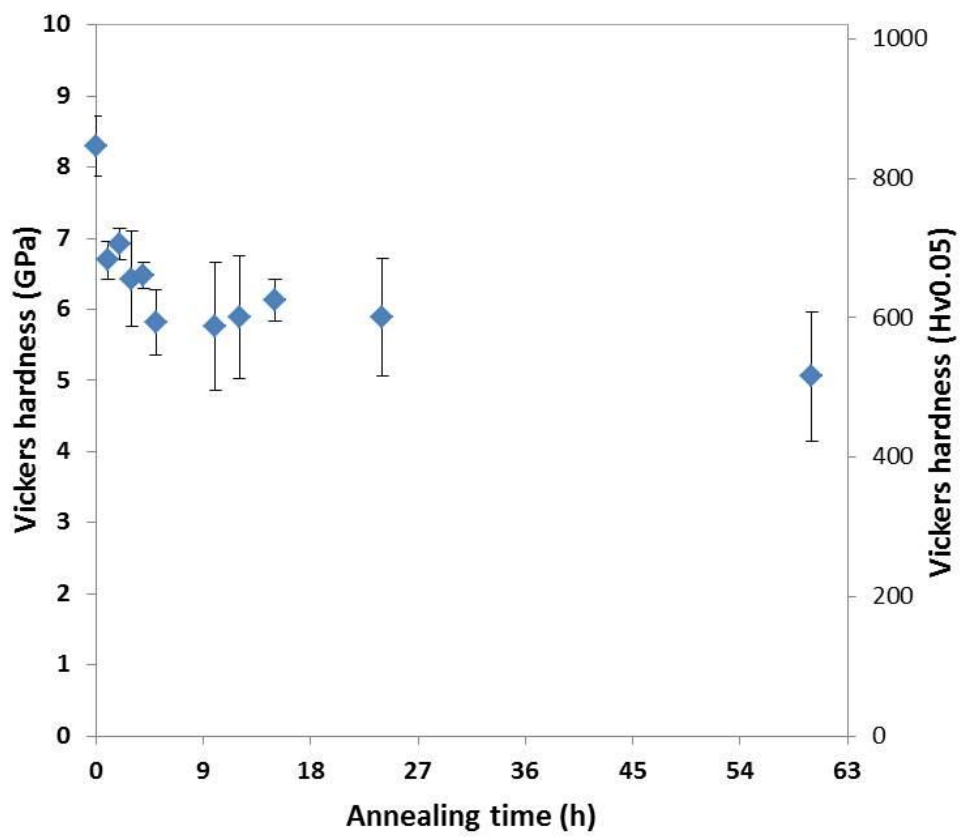


Fig. 2
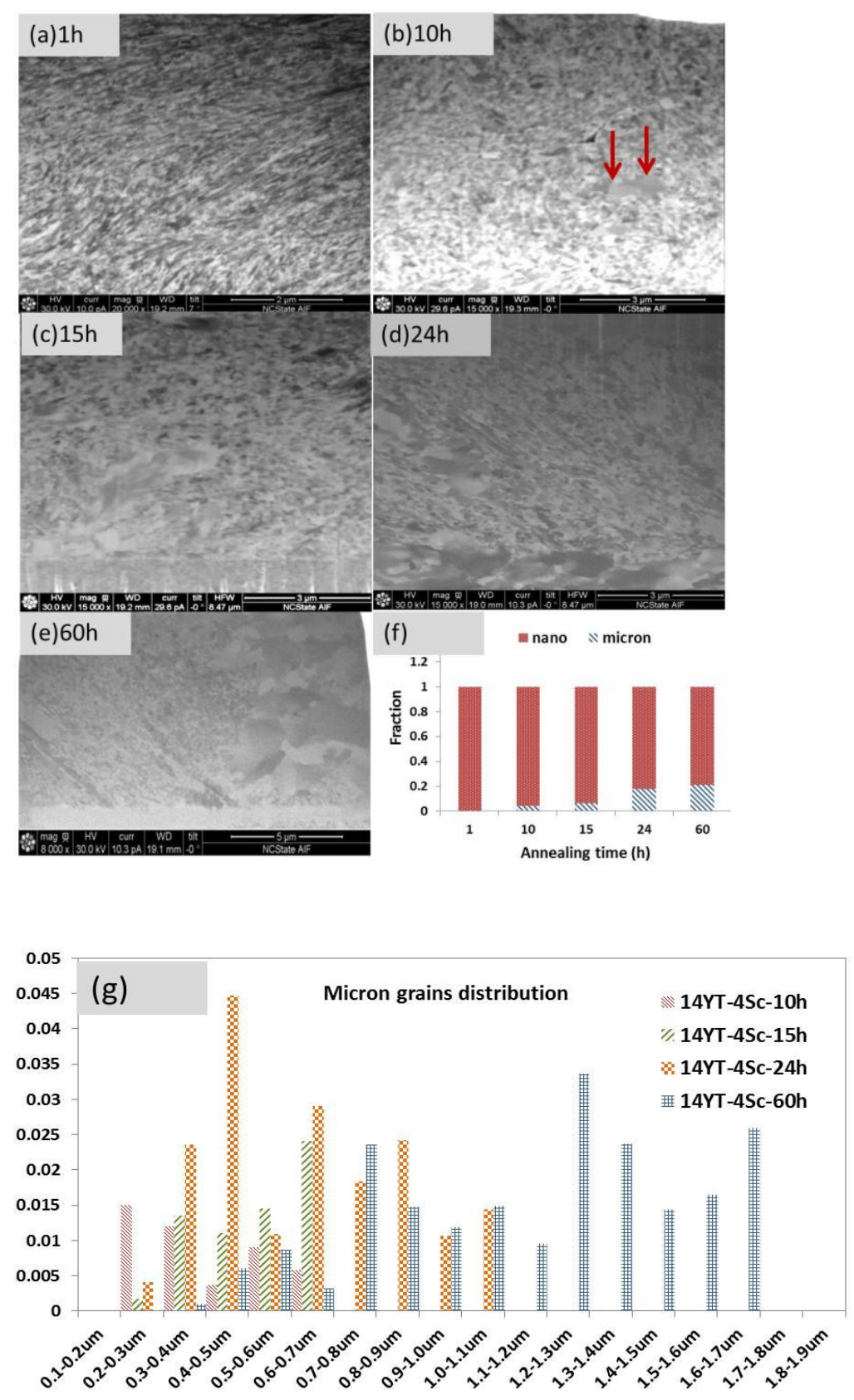
Fig.3

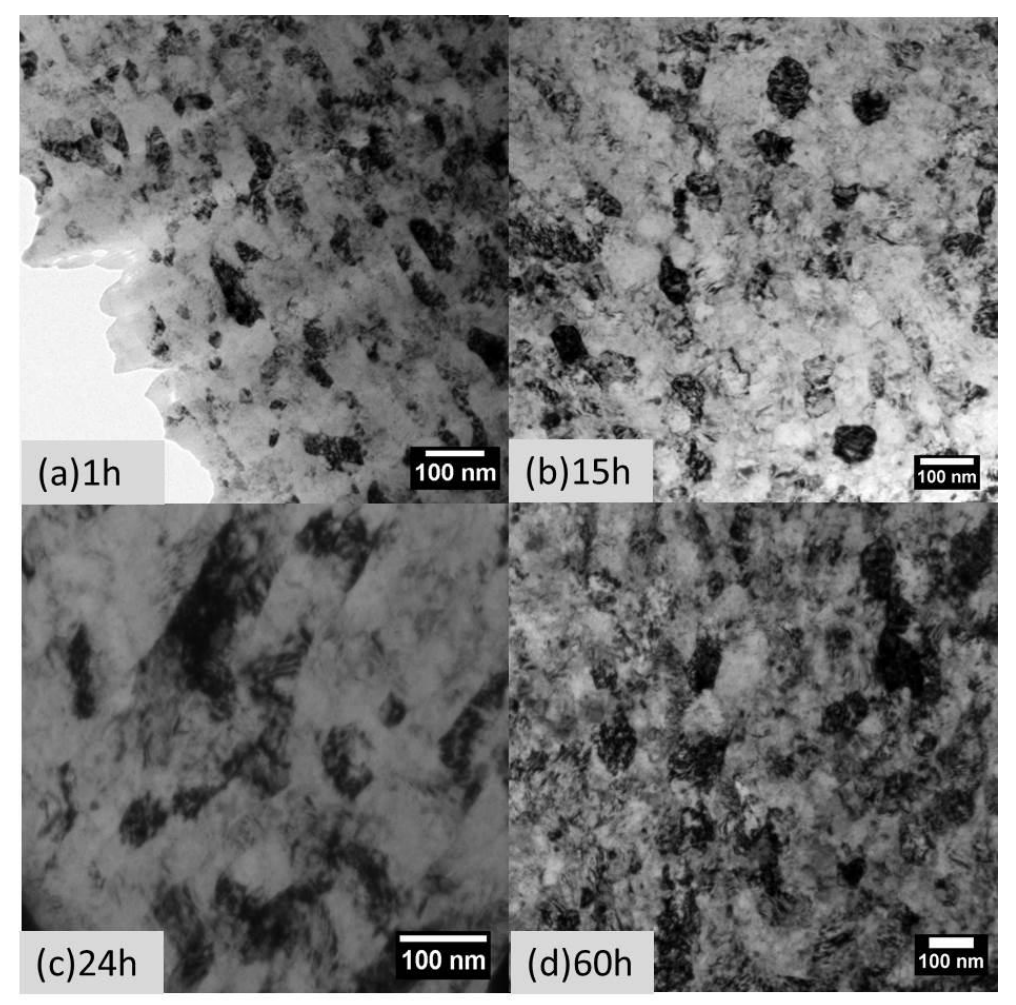


Fig. 4
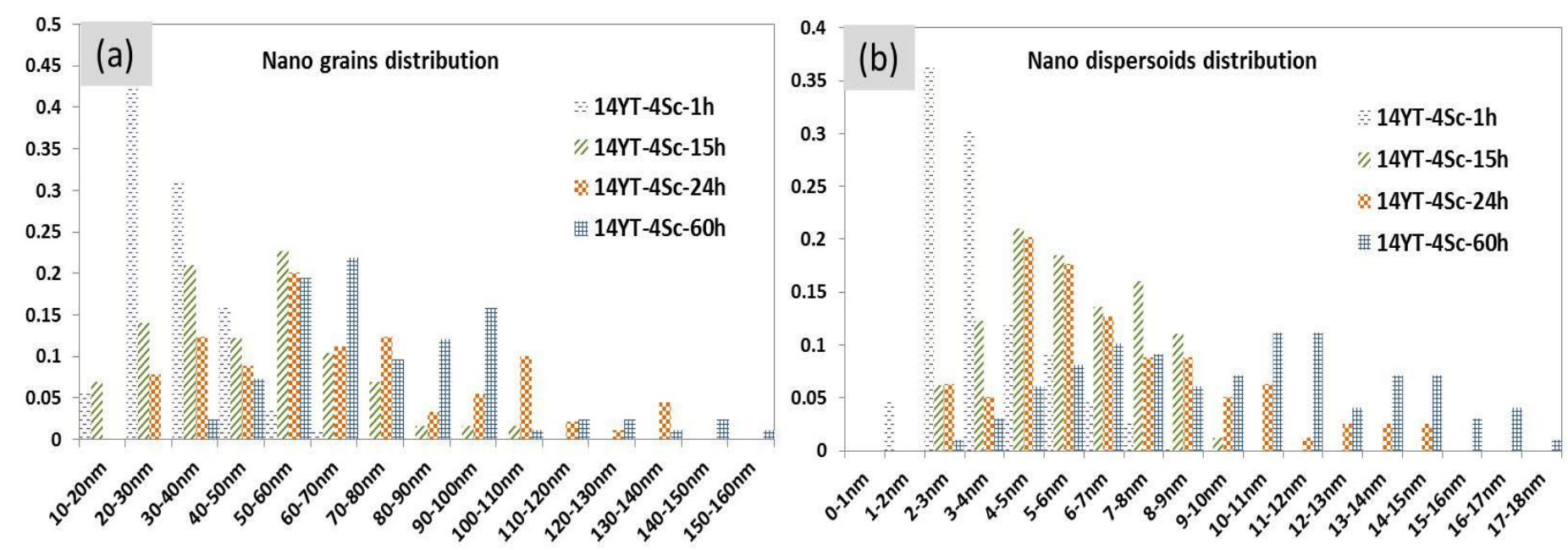
Fig.5(a)

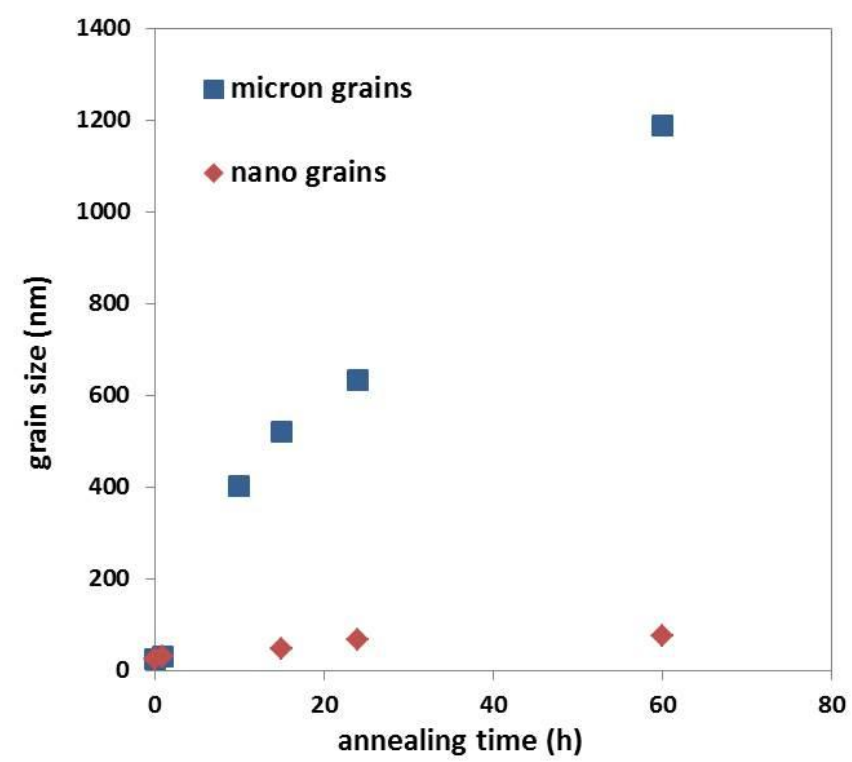

Fig.5(b)

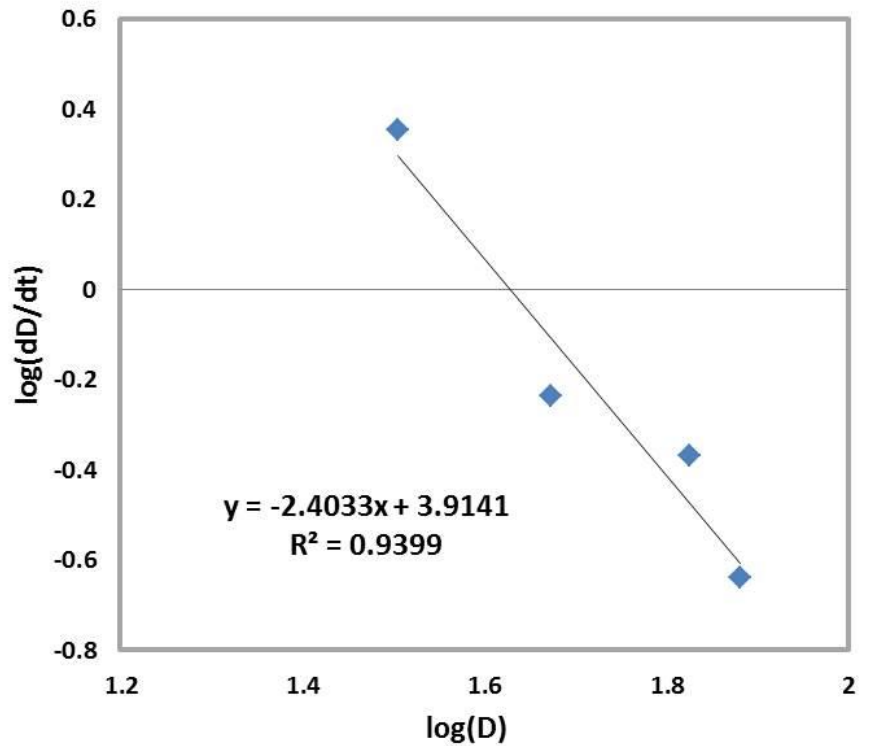


Fig.6

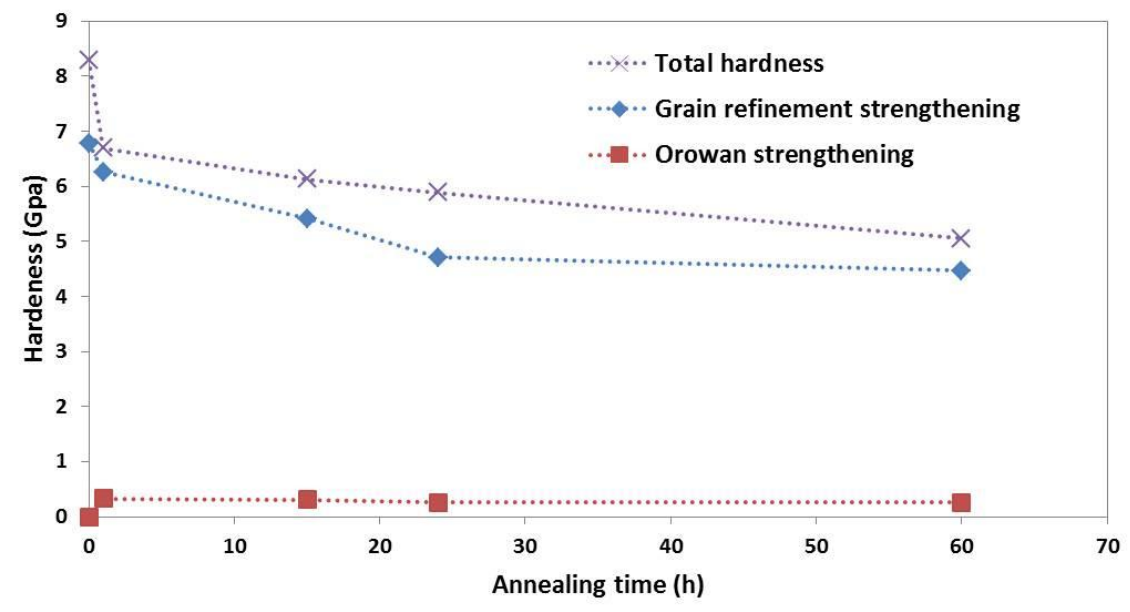


Fig.7

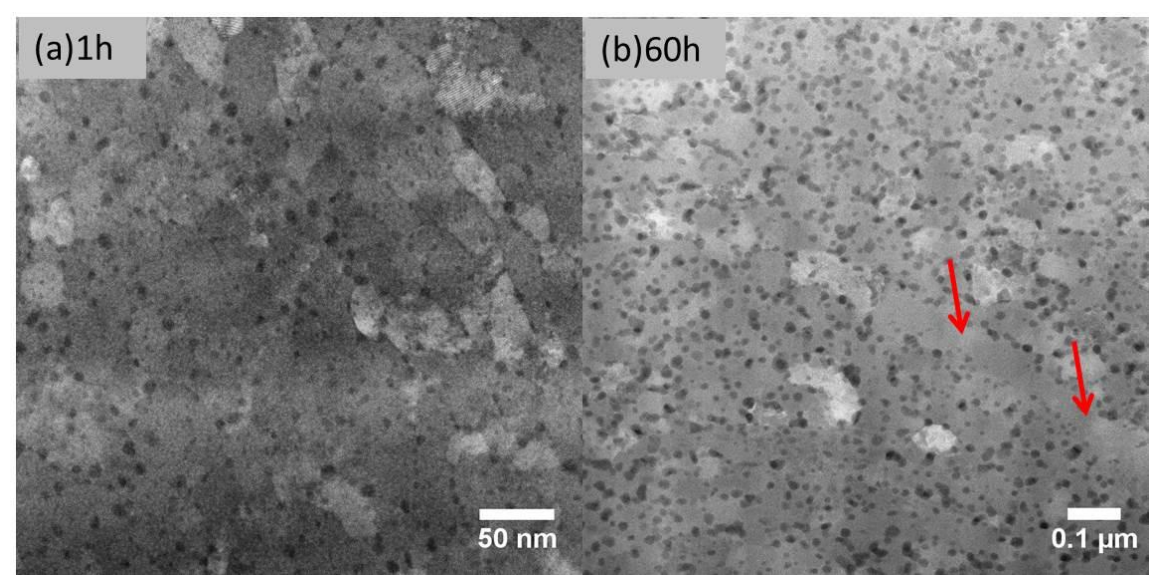

Fig. 8

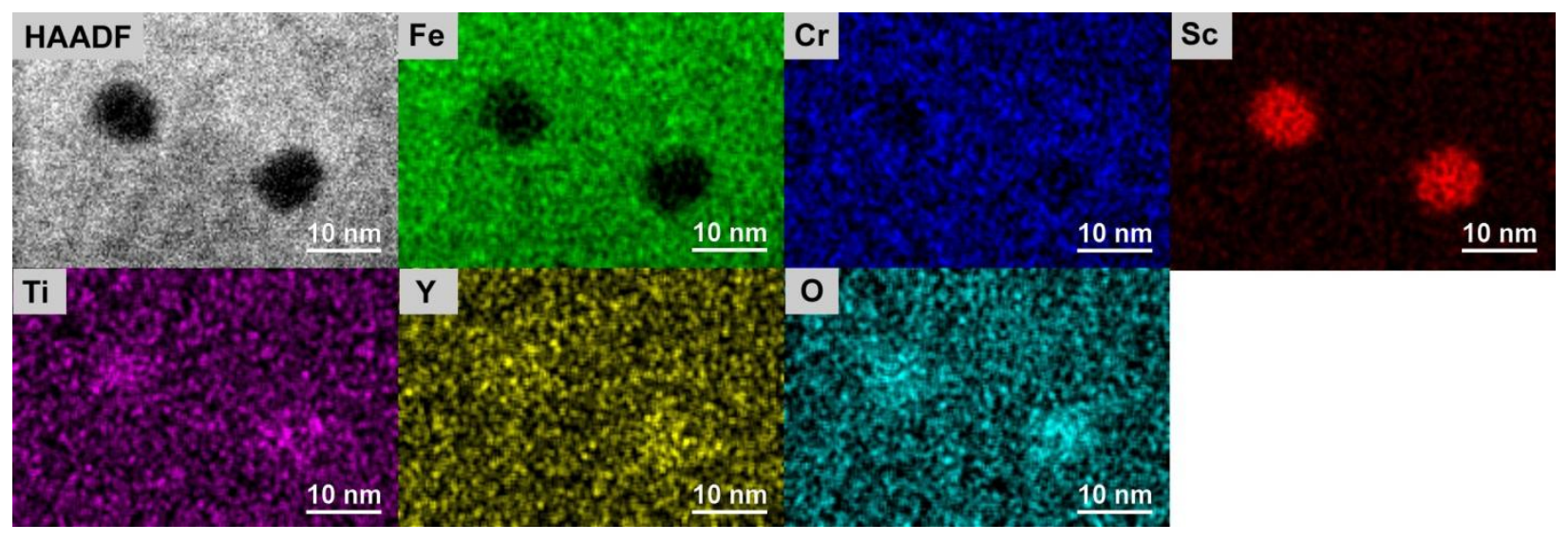

